\title{
GMR
}

\section{Cloning of superoxide dismutase from post-harvest Hami melon and quantitative expression analysis before and after disease}

\author{
C.H. Shan ${ }^{1,2}$, F.X. Tang ${ }^{2}$, W. Chen ${ }^{1}$ and W.R. $\mathrm{Ma}^{2}$ \\ ${ }^{1}$ School of Science and Technology, Jiangnan University, Wuxi, Jiangsu, China \\ ${ }^{2}$ Food College of Shihezi University, Shihezi, Xinjiang, China \\ Corresponding author: W. Chen \\ E-mail: shan771128@163.com
}

Genet. Mol. Res. 14 (4): 18229-18240 (2015)

Received August 31, 2015

Accepted October 2, 2015

Published December 23, 2015

DOI http://dx.doi.org/10.4238/2015.December.23.10

\begin{abstract}
Primers were designed according to the Cu/Zn-SOD gene sequences of cloned Cucurbits plants (cucumbers and watermelons) available in NCBI. Total RNA from Hami melon pulp was used as a template. Following RT-PCR amplification, a 403-bp fragment of the Hami melon Cu/Zn-SOD gene was obtained. According to alignment in BLAST and phylogenetic tree analysis, the cloned gene fragment was confirmed to be the Hami melon Cu/Zn-SOD gene sequence. Real-time fluorescence quantitative expression analysis indicated that there were differences in the expression of SOD mRNA expression before and after infection by blue mold. mRNA expression was maximal 24-h after infection, indicating that the product of the SOD gene plays an important role in the rotting and degeneration of Hami melons as a consequence of bacterial infection during the preservation period.
\end{abstract}

Key words: Hami melon; Superoxide dismutase; Gene cloning; Real-time fluorescence quantitative PCR 


\section{INTRODUCTION}

Superoxide dismutase (SOD) is a protein with specific biological catalytic functions. Based on the metal cofactor present at the catalytic site, SOD can be divided into three types: Cu/Zn-SOD, Mn-SOD, and Fe-SOD. Cu/Zn-SOD is the major type, representing $86 \%$ of the total SOD isoforms. Previous studies have indicated that SOD1, or CuZn-SOD was the first of these enzymes to be characterized, and that it is a copper and zinc-containing homodimer found almost exclusively in intracellular cytoplasmic spaces (Zelko et al., 2002). It forms a dimer with the hydrophobic phase through a non-covalent bond between the two subunits.

Under environmental stress, SOD activity is accelerated (Miszalski, 1995; Rubio et al., 2002; Mutlu et al., 2009; Faize et al., 2011), and expression of the Cu/Zn-SOD gene can be induced in plants (Bagnoli et al., 2002). Cu/Zn-SOD can directly reverse the oxidative damage induced by $\mathrm{H}_{2} \mathrm{O}_{2}$ (Mann and Keilin, 1938). This indicates that SOD plays an important role during antioxidant damage to plants (McCord and Fridovich, 1969; Bowler et al., 1992; Payton et al., 2001; Chen and Tan, 2007; Gill and Tuteja, 2010). Hami melon is a special variety in Xinjiang, but it rots easily during preservation and transportation. SOD is an antioxidant agent in Hami melons and is the primary substance that eliminates free radicals. The level of SOD inside an organism is a direct index of ageing and death (Bueno et al., 1995).

The Jiashi melon, a late maturing type of Hami melon produced in Xinjiang, was used in the present study. A novel Cu/Zn-SOD gene was obtained by primer design and cloning. The realtime fluorescence quantitative PCR technique was used to determine the levels of SOD mRNA expression (Zhu et al., 2006). This study provides a foundation for further disease resistance research in Hami melon.

\section{MATERIAL AND METHODS}

\section{Hami melon samples}

Samples of late maturing Jiashi melon were used. In October, the samples were purchased from Jiashi County and preserved in the refrigerated warehouse of the School of Food Science, Shihezi University. Jiashi melons of an adequate size with no epidermal damage were selected and divided into two groups: a control group and an experiment group. A 1-cm borer was used to drill a hole $1-1.5 \mathrm{~cm}$ deep in the surface of the melons in the experiment group. Melons were inoculated with a precultivated blue mold culture. The hole was wrapped with cling film. Samples were collected before inoculation and 12, 24, 48, 60, 72 and $96 \mathrm{~h}$ afterwards. Every group contained three duplicates.

\section{Extraction of total RNA and reverse transcription}

Total RNA was extracted from Hami melons using the TRIzol method (Wang et al., 2007). The samples were ground quickly in liquid nitrogen. TRIzol (Invtrogen, USA), containing phenol and guanidinium isothiocyanate, was added. After a 10-min pyrolysis period to release the nucleic acid-protein compounds, chloroform was added and the mixture was shaken violently for 3 min to guarantee the separation of nucleic acid from protein. Isopropanol was added and the samples were precipitated for $15 \mathrm{~min}$. The sediment was washed three times in $75 \%$ alcohol to remove salt residues. 
Samples were then placed on a clean bench at room temperature or in a vacuum state for natural volatilization for 5-7 min to dry. This step should be minimised to prevent over-drying or reduced RNA solubility. Next, RNA was dissolved in DEPC-treated sterile water and preserved at $-70^{\circ} \mathrm{C}$.

\section{Primer design}

Previous studies showed that large genetic similarity exists between Cucurbitaceae crops (Danin Poleg et al., 2001). Watermelon and muskmelon share $>70 \%$ identity (Pasha and Sen, 1998). Danin Poleg et al. (2001) found that out of 34 pairs of SSR primers in muskmelon, 18 could be located on a genetic map of the cucumber, indicating a high level of conservatism between cucumber and muskmelon. To build a BAC library of watermelon, 38 out of 46 pairs of SSR primers in muskmelon (82\%) could yield PCR products, indicating high conservatism between watermelon and cucumber (Joobeur et al., 2006). Therefore, this study used Cu/Zn-SOD gene sequences from cucumber and watermelon to design the primers. GAPDH was used as an internal reference gene for PCR analysis. The primer sequences are provided in Table 1.

Table 1. Primers designed to amplify Cu/Zn-SOD gene sequences of Hami melon.

\begin{tabular}{|c|c|}
\hline Primer name & The sequence of primer $\left(5^{\prime}-3^{\prime}\right)$ \\
\hline \multirow[t]{2}{*}{ GAPDH } & F1: 5' AAAGACTGGAGAGGTGGAAGAGC 3' \\
\hline & R1: 5' TCAACGGTAGGAACACGGAAAGA 3' \\
\hline \multirow[t]{7}{*}{ Cucumis sativus Cu/Zn-SOD } & F1: 5' GAAGACGATGGTCCAACAACAGTAAAT 3' \\
\hline & F2: 5' ATTGTAGATAACCAGATTCCTCTTAGCGGC 3' \\
\hline & R1: 5' CTAACGCAGCCCTCACATTTCATA 3' \\
\hline & R2: 5' GGAGT AAGACCGACAACACCACA 3' \\
\hline & R3: 5' ACTGAGTTCATGACCTCCTTTTCCT 3' \\
\hline & R4: 5' GTTAAACTGAGTTCATGACCTCCTTTTCCTAG 3' \\
\hline & R5: 5' GGTTAAACTGAGTTCATGACCTCCTTTTCCTAG 3' \\
\hline \multirow[t]{9}{*}{ Citrullus lanatus Cu/Zn-SOD } & F1: 5' TCACGCTCACCCAAGAAGACG 3' \\
\hline & F2: 5' CCAAGAAGACGATGGTCCAACAACAGTAA 3' \\
\hline & F3: 5' GGCTTCACGGATTCCATCTTCACGAG 3' \\
\hline & F4: 5' TTCACGAGTATGGAGACACAACAAATGG 3' \\
\hline & R1: 5' TTGGCAATTATGTTTCCCAGGTCACC 3' \\
\hline & R2: 5' TCCATCAGCATTGGCAATTATGTTTC 3' \\
\hline & R3: 5' ATCTACAATGGTTGCCTCCGCTACTC 3' \\
\hline & R4: 5' GGAATCTGGGTATCTACAATGGTTGCCTC 3' \\
\hline & R5: 5' GCTGAGAGGAATCTGGGTATCTACAATG 3' \\
\hline
\end{tabular}

\section{Cloning and sequence analysis of PCR products}

The PCR reaction conditions were as follows: predegeneration at $94^{\circ} \mathrm{C}$ for 3 min, degeneration at $94^{\circ} \mathrm{C}$ for $30 \mathrm{~s}$, annealing at $54^{\circ} \mathrm{C}$ for $30 \mathrm{~s}$, extension at $72^{\circ} \mathrm{C}$ for $1 \mathrm{~min} ; 30$ cycles, extension at $72^{\circ} \mathrm{C}$ for $10 \mathrm{~min}$.

The PCR products were recovered by $1 \%$ agarose gel electrophoresis, ligated into the pMD18-T vector, and transformed into Escherichia coli DH5a competent cells. Amp resistance and X-gal/IPTG blue-white screening was performed. White colonies were selected for subsequent liquid culture. PCR was employed to detect positive clones and sequencing.

\section{Real-time fluorescence quantitative PCR detection of the Hami melon SOD gene}

Real-time fluorescence quantitative PCR (ABI, USA) was performed to amplify sequences of the Hami melon SOD gene (Wang and Hong, 2004), using GAPDH as the internal reference gene. 
The GAPDH primer sequence used was as follows: $F$ primer sequence: 5' CCGTGTTCCT ACCGTTGATGTC 3'; R primer sequence: 5' CAGTGTACCCCAAAATTCCCTTC 3'. The SOD primer sequence used was as follows: $F$ primer sequence: 5' TCACGCTCACCAAGAAGACG 3' R primer sequence: 5' TCCATCAGCATTGGCAATTATGTTTC 3'.

The PCR mix contained: $12.5 \mu \mathrm{L} 2 \mathrm{X}$ Ex TaqMix, $0.75 \mu \mathrm{L}$ primer Mix $(10 \mu \mathrm{M}), 1.25 \mu \mathrm{L} 20 \mathrm{X}$ Eva_green, $1 \mu \mathrm{L}$ template cDNA, $9.5 \mu \mathrm{L}$ RNase-free water in 0.2-mL thin-walled PCR tubes. The mixture was shaken well, numbered, and placed in the quantitative PCR instrument.

The PCR conditions were as follows: $95^{\circ} \mathrm{C}$ for $5 \mathrm{~min}$ and $95^{\circ} \mathrm{C}$ for $30 \mathrm{~s}, 40$ cycles at $65^{\circ} \mathrm{C}$ for $25 \mathrm{~s}$. Every treatment was performed in triplicate. The process was conducted on a Miniopticon real-time PCR instrument.

\section{Data processing}

Gene expression was calculated according to the relative quantification method (Nolan et al., 2006). Relative expression of the object gene was calculated as follows: Re.I Exp $=2^{-\Delta \Delta C t}$, where $\Delta \mathrm{Ct}=\mathrm{Ct}(\mathrm{SOD})-\mathrm{Ct}(\mathrm{GAPDH})$.

\section{RESULTS AND DISCUSSION}

\section{Total RNA extraction}

Figure 1 shows that the 28sRNA, 18sRNA, and 5sRNA bands amplified from Hami melon samples and obtained by the TRIzol method were clear and intact. The quality of RNA extracted from samples No. 2, 3, and 5 was good, and could be used in the subsequent experiment following treatment with DNA enzymes.

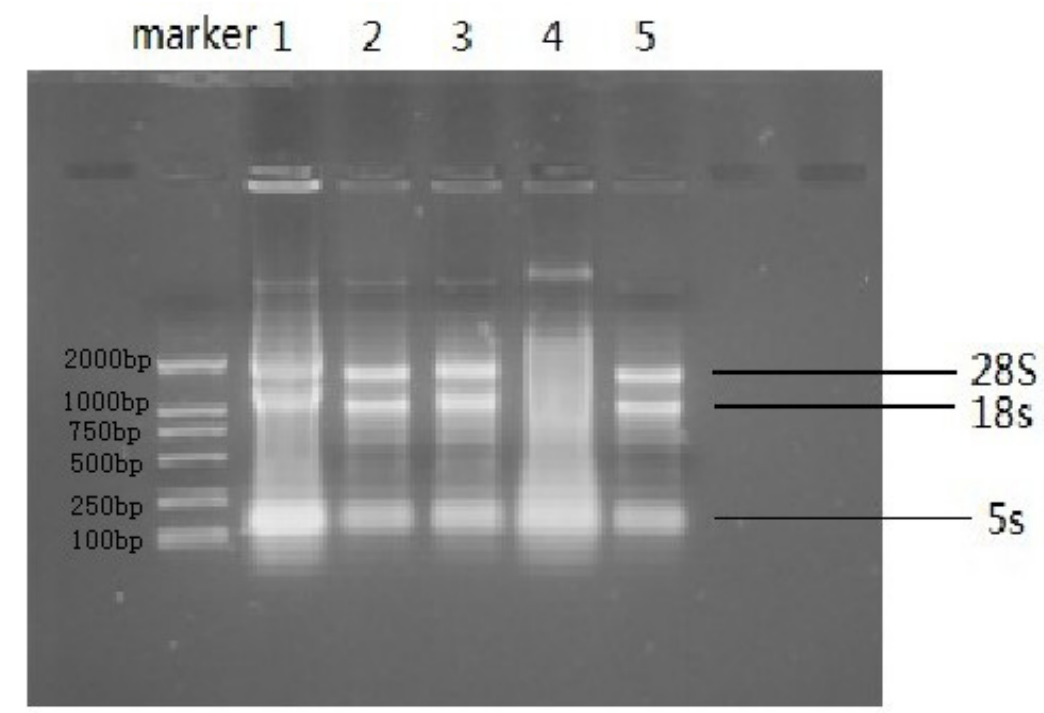

Figure 1. Total RNA extraction from Hami melons. Marker: DL2000 DNA molecular weight; lane 1 is the epidermal tissue of Hami melon; lanes 2-3 is the green pulp tissue; lane 4 is the junction of green and red pulp tissue; lane 5 is the red pulp tissues of Hami melon. 


\section{RT-PCR detection}

Figure 2a shows that lane 1-2 contained a 137-bp GAPDH gene fragment as expected; lane 3 contained no amplified product for cucumber F1R1. Figure $2 b$ indicates that lanes 1-5 represent the five pairings between watermelon F1 and R1-R5 and that 230-260-bp fragments were amplified; lanes 6-10 are the five pairings between watermelon F2 and R1-R5, and 230260bp fragments were amplified; lanes 11-15 represent the five pairings of watermelon F3 and R1$\mathrm{R} 5$, and dimers were amplified, indicating that F3 primers did not satisfy the requirements. Lanes 16-20 represent the five pairings of watermelon F4 and R1-R5; except for F4R3, which shows mismatching, and other matching met the requirements.

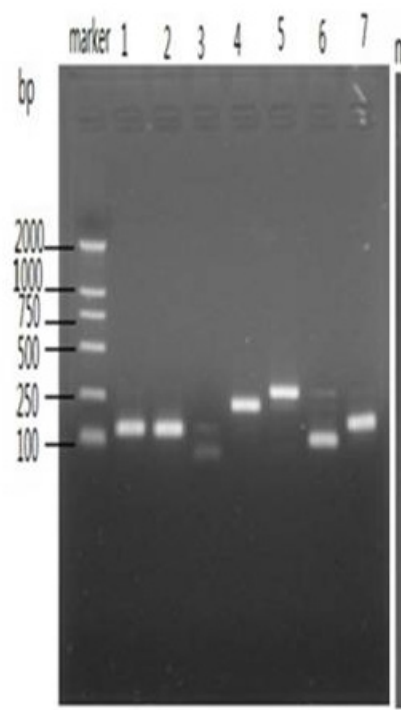

a

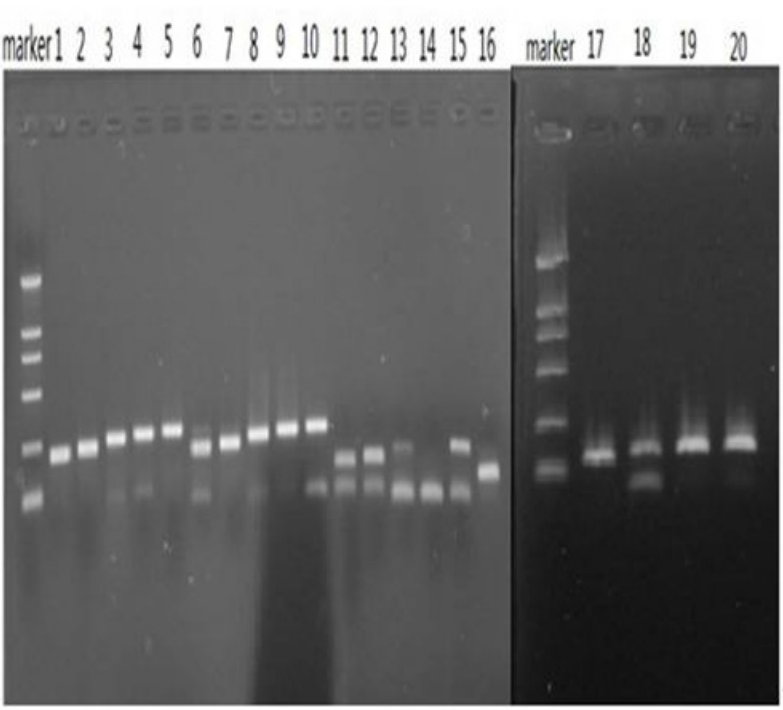

b

Figure 2. RT-PCR results. Marker: DL2000DNA molecular weight standard. A. Lanes 1, 2 are GAPDH (internal reference gene); lane 3 is cucumber F1R1; lanes 4-7 are four pairings between cucumber F2 and R2-R5. B. Lanes 1-5 are five pairings between watermelon $\mathrm{F} 1$ and $\mathrm{R} 1-\mathrm{R} 5$; lanes $6-10$ are five pairings between watermelon $\mathrm{F} 2$ and $\mathrm{R} 1-\mathrm{R} 5$; lanes 11-15 are five pairings between watermelon F3 and R1-R5; lanes 16-20 are five pairings between watermelon F4 and R1-R5.

\section{Sequence analysis and homologous comparison}

\section{Sequencing result analysis}

Sequenced fragments were assembled and the 403-bp Hami melon Cu/Zn-SOD gene sequence was obtained. ORF software was applied for the analysis, and a peptide chain encoding 66 amino acids was obtained (Figure 3). On the basis of the amino acid sequence, it was inferred that this sequence encoded 133 amino acids. The encoded protein was confirmed to be a member of $\mathrm{Cu} / \mathrm{Zn}-\mathrm{SOD}$ family following alignment in NCBI using BLAST (Figure 4). It was named $\mathrm{HmCu}$ / $\mathrm{Zn}-\mathrm{SOD}$. 
1 TTCACGCTCACCAAGAAGACGATGGTCCAACATCAGTCAATGTGCGTATTACCGGGCTCA

$\begin{array}{llllllllllllllllllll}\mathrm{H} & \mathrm{A} & \mathrm{H} & \mathrm{Q} & \mathrm{E} & \mathrm{D} & \mathrm{D} & \mathrm{G} & \mathrm{P} & \mathrm{T} & \mathrm{S} & \mathrm{V} & \mathrm{N} & \mathrm{V} & \mathrm{R} & \mathrm{I} & \mathrm{T} & \mathrm{G} & \mathrm{L}\end{array}$

61 CCCCAGGTCCTCATGGATTCCATCTTCATGAATTTGGAGACACAACAAATGGATGCATTT $\begin{array}{lllllllllllllllllllll}T & P & G & P & H & G & F & H & L & H & E & F & G & D & T & T & N & G & C & I\end{array}$ 121 CTACAGGAGCACATTTCAATCCTAACAAGTTAACGCATGGTGCTCCTGAGGACGAAATCC $\begin{array}{lllllllllllllllllllll}S & T & G & A & H & F & N & P & N & K & L & T & H & G & A & P & E & D & E & I\end{array}$

181 GACATGCGGGTGACCTGGGAACATAATTGCCAATGCTGATGGAGTAGCAGAGGCAACCA

$\begin{array}{llllllllllllllllllll}R & H & A & G & D & \text { L } & G & N & I & I & A & N & A & D & G & V & A & E & A & T\end{array}$

241 TTGTAGATAACCAGATTCCTCTTAGCGGCCCCAATTCTGTAGTTGGAAGAGCCTTTGTGG

\begin{tabular}{lllllllllllllllllllll}
$I$ & $V$ & $D$ & $N$ & $Q$ & $I$ & $P$ & $L$ & $S$ & $G$ & $P$ & $N$ & $S$ & $V$ & $V$ & $G$ & $R$ & $A$ & $F$ & $V$ \\
\hline
\end{tabular}

301 TACATGAGCTTGCGGATGATCTAGGAAAAGGAGGTCATGAACTCAGTTTAACCACTGGCA \begin{tabular}{llllllllllllllllllll}
$V$ & $H$ & $E$ & L & A & D & D & L & $G$ & K & $G$ & $G$ & $H$ & E & L & S & L & T & T & $G$ \\
\hline
\end{tabular}

361 ATGCGGGTGGAAGATTGGCATGTGGTGTTGTCGTCTTA CTCCC

$$
\begin{array}{lllllllllllllll}
N & A & G & G & R & \text { L } & \text { A } & \text { C } & G & \text { V } & \text { V } & \text { V } & \text { L } & \text { L } \\
\hline
\end{array}
$$

Figure 3. cDNA sequence and deduced amino acids of $\mathrm{HmCu} / \mathrm{Zn}-\mathrm{SOD}$ from Hami melon.

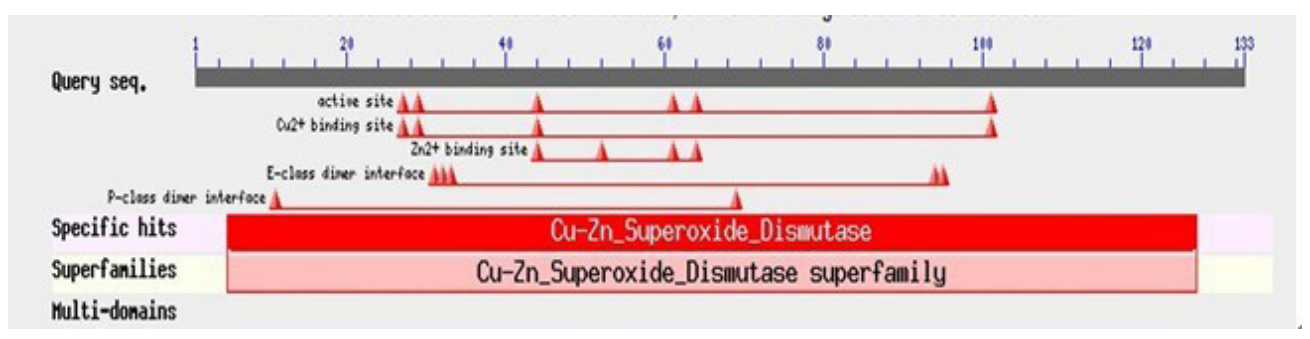

Figure 4. Amino acid sequence and structure domain analysis of $\mathrm{HmCu} / \mathrm{Zn}-\mathrm{SOD}$.

\section{Sequence similarity analysis}

Results from the BLAST similarity analysis and ClustaLW sequence alignment indicate that the nucleotide sequence of the cloned Hami melon $\mathrm{Cu} / \mathrm{Zn}-\mathrm{SOD}$ gene is highly similar to that of the Cu/Zn-SOD gene from several plants (Ji et al., 2011). Table 2 shows that the base similarity of Hami melon and cucumber, watermelon, upland cotton, sunflower, grape, alfalfa, lily, and daylily is $98,93,84,81,82,85,81$, and $82 \%$, respectively.

Table 2 shows that the amino acid sequence similarity of Hami melon and several plants is $96,94,92,91,88,90,89$, and $91 \%$, respectively. These data confirm that the obtained sequence is indeed that of the Cu/Zn-SOD gene sequence from Hami melon. This indicates that SOD has undergone slight base changes during its evolution. The protein structure of SOD is stable (Wang et al., 2010). 
Table 2. Sequences used for cloning and identity withthe Cu/Zn-SOD gene sequence in other species.

\begin{tabular}{|c|c|c|c|c|}
\hline $\begin{array}{l}\text { GenBank accession } \\
\text { No. of nucleotide }\end{array}$ & $\begin{array}{l}\text { GenBank accession } \\
\text { No. of protein }\end{array}$ & Species & Identity of nucleotide/\% & Identity of amino acid/\% \\
\hline XM_004167740.1 & XP_004167788.1 & Cucumis sativus & 98 & 96 \\
\hline AY5666999.1 & AAS̄̄72937.1 & Citrullus lanatus & 93 & 94 \\
\hline DQ120514.1 & AAZ41971.1 & Gossypium hirsutum & 84 & 92 \\
\hline AF172568.1 & СAH06449.1 & Helianthus annuus & 81 & 91 \\
\hline AF056622.1 & NP_001268067.1 & Vitis vinifera & 82 & 88 \\
\hline XM004287502.1 & XP_004287550.1 & Fragaria vesca & 85 & 90 \\
\hline AY898945.1 & AAX07164.1 & Lilium hybrid & 81 & 89 \\
\hline D49486.1 & BAA19675.1 & Solidago canadensis & 82 & 91 \\
\hline
\end{tabular}

\section{Phylogenetic tree analysis}

MEGA4 software was used to construct a phylogenetic tree of eight plants based on the $\mathrm{Cu} / \mathrm{Zn}-\mathrm{SOD}$ gene sequences, including those from Hami melon and cucumber.

Figure 5 indicates that Hami melon Cu/Zn-SOD is highly homologous to cucumber and watermelon $\mathrm{Cu} / \mathrm{Zn}$-SOD within the Cucurbitaceae family, and shares moderate homology with members of the Liliaceae and Malvaceae family; and little homology with grape, sunflower, and daylily. Sunflower and daylily both belong to Compositae families, and share close homology. This is consistent with the previous finding that $\mathrm{Cu} / \mathrm{Zn}-\mathrm{SOD}$ has been highly conserved throughout evolution (Ding et al., 2009). There is high homology between Cu/Zn-SOD from the same and different species.

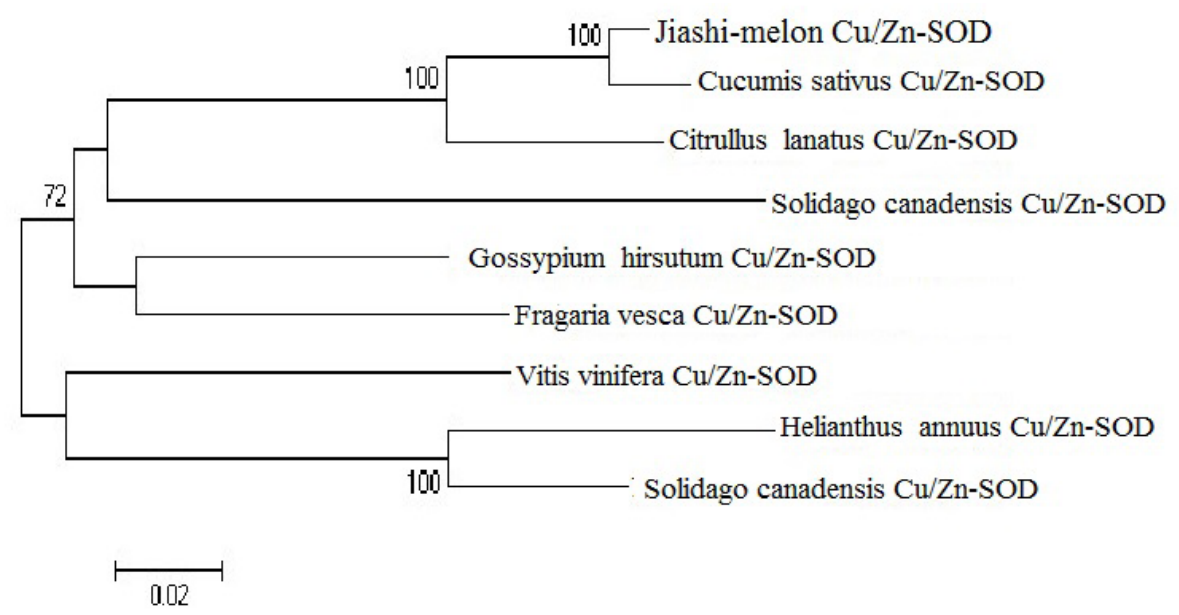

Figure 5. Phylogenetic tree of Cu/Zn-SOD from Hami melon.

\section{Quantitative expression analysis of SOD}

In order to determine differences in SOD gene expression before and after infection, fruit pulp tissues from Jiashi and late maturing Hami melon were used for RNA extraction before and $12,24,48,60$, and $72 \mathrm{~h}$ after inoculation with blue mold. GAPDH was used as an internal reference gene for real-time fluorescence quantitative expression analysis. 
Figure 6 shows the shape of the dynamic fluorescence curve obtained during PCR and the standard melting curves of the SOD gene. The dissociation curves of the two genes each had only one peak, indicating that the product was unique and that the primers were highly specific. The amplification curves indicated that the curves have a clear inflexion point. Thus the cells were at the logarithmic phase. The parallelism of the amplification curves was good and the baseline was steady.
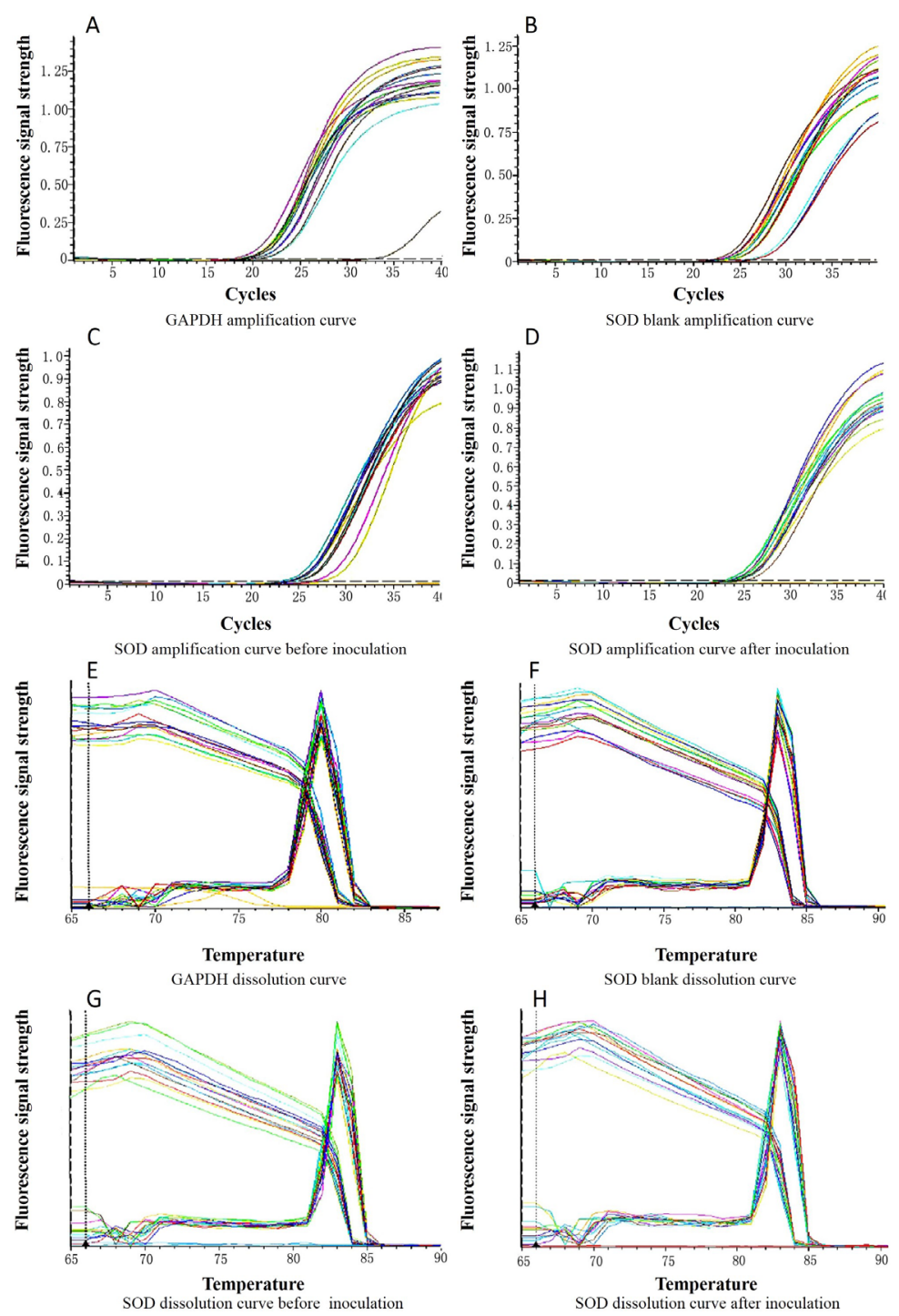

Figure 6. Fluorescence curve obtained during PCR and standard melting curves of SODsubject to different treatments. A. GAPDH amplification curve. B. SOD blank amplification curve. C. SOD amplification curve before inoculation. D. SOD amplification curve after inoculation. E. GAPDH dissolution curve. F. SOD blank dissolution curve. G. SOD dissolution curve before inoculation. H. SOD dissolution curve after inoculation. 
The $2^{-\Delta \Delta C t}$ method was used to calculate relative expression of the SOD gene at different time points after inoculation. The $0 \mathrm{~h}$ without inoculation time point was used for the control group and defined as 1. Quantitative analysis of SOD mRNA expression during four different phases was conducted. The standard curves, dissociation curves, and amplification curves for fluorescence quantitative expression analysis all met the requirements.

Figures 7-9 show the change in SOD gene expression before and after inoculation with blue mold. Expression of SOD mRNA increased at 96-h during the preservation period compared with that detected in the blank control. SOD expression in the non-inoculated part of the same melon increased slowly and that of the inoculated part first increased, then decreased, and then slightly increased again. Expression of the SOD gene was highest at $72 \mathrm{~h}$ without inoculation, then at $24 \mathrm{~h}$, and then $48 \mathrm{~h}$. After inoculation, the highest expression was detected at $24 \mathrm{~h}$. This is consistent with the change in SOD activity observed before and after inoculation of the melons, as shown in previous studies. The change in SOD activity in Hami melons, and gene expression are positively correlated, indicating that SOD plays a significant role in the change in quality of these melons during preservation. This may be due to SOD being a peroxidase, which eliminates free radicals. The change is closely related to the aging of the body and to environmental stress (OkadoMatsumoto and Fridovich, 2001; Faize et al., 2011). After bacterial inoculation, the organism is subjected to external stress; expression of the SOD increases rapidly, thus preparing the organism for the change. Over time, expression of SOD falls, indicating that the organism has undergone great changes, including the accumulation of free radicals, and severe cell damage that exceeds the capacity of SOD.

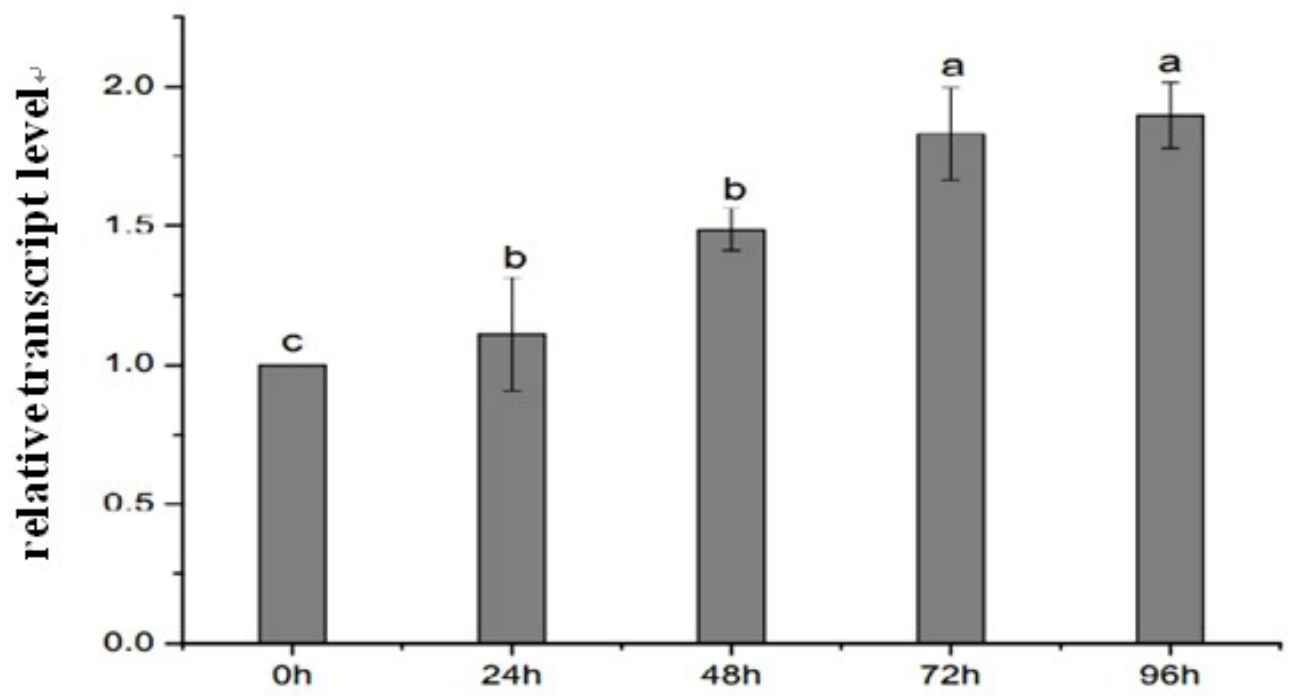

Figure 7. Relative expression amount of SOD during in fail inoculation Hami melon storage. Values with different letters differ significantly $(P<0.05)$.

SOD is part of a refined and complicated defense system against reactive oxygen species. During the early preservation period of Hami melons, SOD activity increases rapidly, possibly due to the protective reaction of Hami melon tissues. Aging increases free radicals, causing SOD activity to increase. With the prolonged preservation time, the free radical elimination system is 
damaged, the SOD activity declines, and aging accelerates. The increased SOD activity in Hami melons during the early preservation period is possibly a protective reaction that is typical of fruits and vegetables.

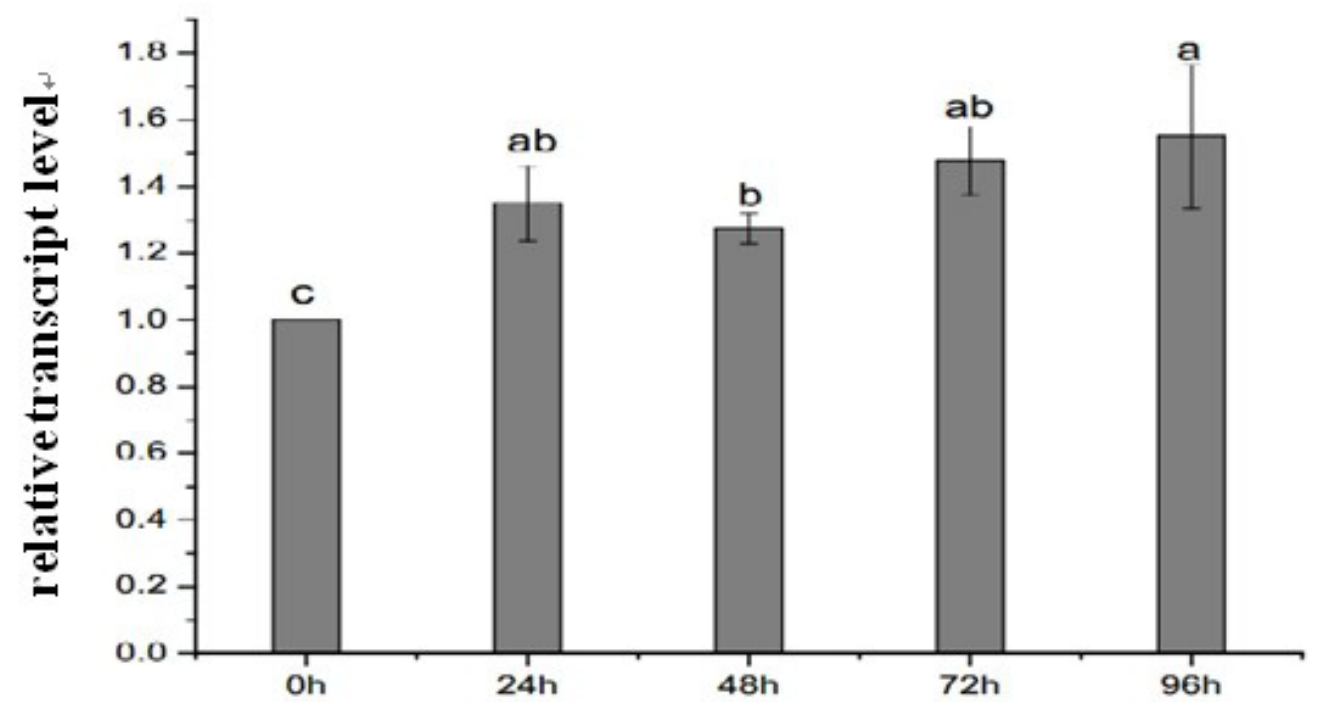

Figure 8. Relative expression amount of SOD during in inoculation blank Hami melon storage. Values with different letters differ significantly $(P<0.05)$.

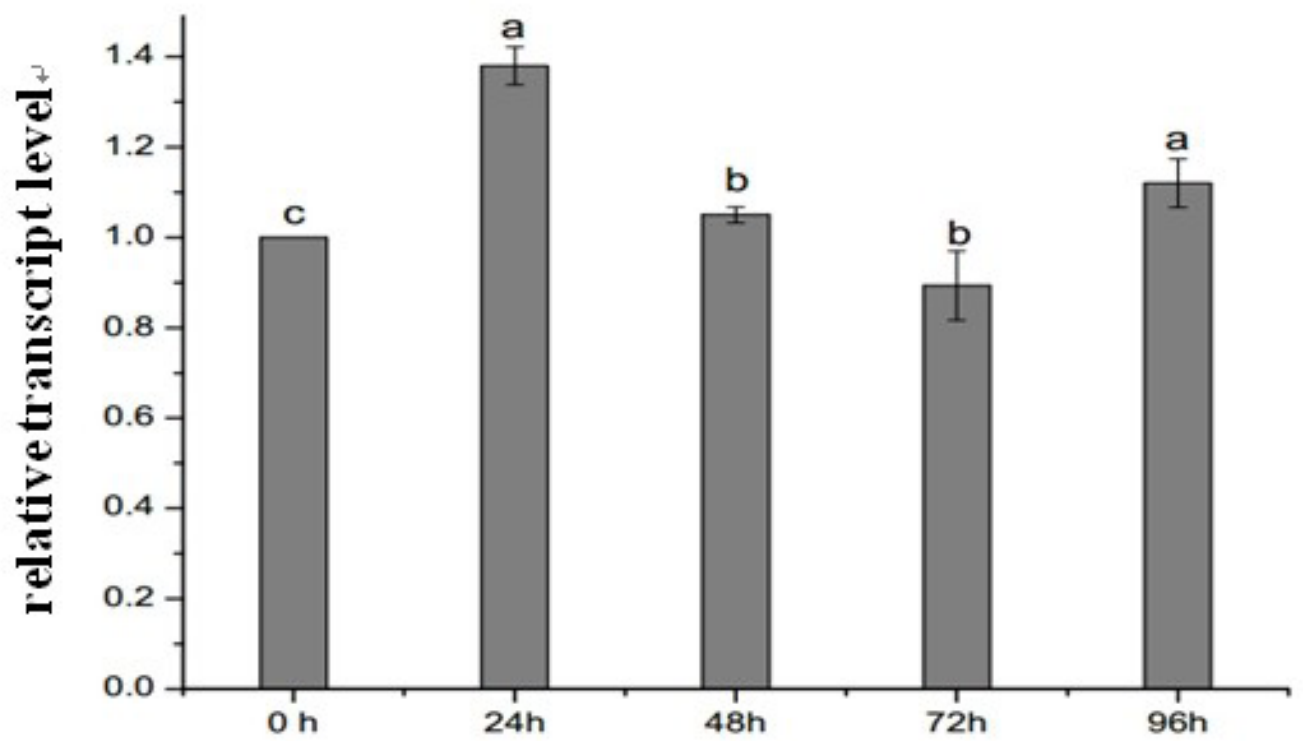

Figure 9. Relative expression amount of SOD during in inoculation Hami melon storage. Values with different letters differ significantly $(P<0.05)$. 
The knowledge that SOD mRNA expression in Hami melon changes under different treatments provides a foundation for studies to investigate why SOD activity changes. The change in SOD activity originates at the genetic level. Understanding these changes provides a foundation for the breeding of SOD transgenic plants and better utilization of SOD. It also provides foundation for the establishment of more scientific and reliable experimental methods to study the relationship between the key enzyme changes during the preservation of Hami melons and preservation time.

\section{Conflicts of interest}

The authors declare no conflict of interest.

\section{ACKNOWLEDGMENTS}

Research supported financially by funding from the National Natural Science Foundation of China (\#31360412).

\section{REFERENCES}

Bagnoli F, Giannino D, Caparrini S, Camussi A, et al. (2002). Molecular cloning characterisation and expression of a manganese superoxide dismutase gene from peach (Prunus persica [L] Batsch). Mol. Genet. Genomics 267: 321-328.

Bowler C, Van Montagu M and Inze D (1992). Superoxide dismutase and stress tolerance. Annu. Rev. Plant Physiol. Plant Biol. 43: 83-116.

Bueno P, Varela JW, Gimenez-Gallego G and del Rio LA (1995). Peroxisomal copper, zinc superoxide dismutase. Characterization of the isoenzyme from watermelon cotyledons. Plant Physiol. 108: 1151-1160.

Chen HP and Tan XF (2007). An research overview about Cu-Zn superoxide dismutase (SOD). Economic Forest Res. 25: 59-65.

Danin Poleg Y, Reis N, Tzuri G and Katzir N (2001). Development and characterization of microsatellite markers in Cucumis. Theor. Appl. Genet. 102: 61-72.

Ding QY, Zhang R and Liao XF (2009). Cloning and sequence analysis of cDNA encoding for ACC Synthase from Hami melon. Acta Hortic. 36: 1177-1183.

Faize M, Burgos L, Faize L, Piqueras A, et al. (2011). Involvement of cytosolic ascorbate peroxidase and Cu/Zn-superoxide dismutase for improved tolerance against drought stress. J. Exp. Bot. 62: 2599-2613.

Gill SS and Tuteja N (2010). Reactive oxygen species and antioxidant machinery in abiotic stress tolerance in crop plants. Plant Physiol. Biochem. 48: 909-930.

Ji YY, Hua WP and Wang ZZ (2011). Cloning and bioinformatics analysis of Cu/Zn-SOD gene from Salvia miltiorrhiza Bunge. J. Shanxi Normal Univ. 393: 56-61.

Joobeur T, Gusmini G and Zhang X (2006). Construction of a watermelon BAC library and identification of SSRs anchored to melon or Arabidopsis genomes. Theor. Appl. Genet. 112: 1553-1562.

Mann T and Keilin D (1938). Haemocuprein and hepatocuprein copper-protein compounds of blood and liver in mammals. Proc. R. Soc. B. 126: 303-315.

McCord JM and Fridovich I (1969). Superoxide dismutase: An enzymatic function for erythrocuprein (hemocuprein). J. Biol. Chem. 224: 6049-6055.

Miszalski Z (1995). SOD activity in cam plant kalanchoe daigremontiana exposed to SO2. Acta Soc. Bot. Pol. 6: 251-254.

Mutlu S, Atici Ö and Nalbantoglu B (2009). Effects of salicylic acid and salinity on apoplastic antioxidant enzymes in two wheat cultivars differing in salt tolerance. Biol. Plant 53: 334-338.

Nolan T, Hands RE and Bustin SA (2006). Quantification of mRNA using real-time RT-PCR. Nat. Protoc. 1: $1559-1582$.

Okado-Matsumoto A and Fridovich I (2001). Subcellular distribution of superoxide dismutases (SOD) in rat liver: Cu,Zn-SOD in mitochondria. J. Biol. Chem. 276: 38388-38393.

Pasha MK and Sen SP (1998). Numerical and chemical approaches to taxonomy and relationships. In: Cucurbits (Nayar NM and More TA, eds.). Science Publishers, En-field, 19-32.

Payton P, Webb R, Kornyeyev D, Allen R, et al. (2001). Protecting cotton photosynthesis during moderate chilling at high light intensity by increasing chloroplastic antioxidant enzyme activity. J. Exp. Bot. 52: 2345-2354. 
Rout NP and Shaw BP (2001). Salt tolerance in aquatic macrophytes: possible involvement of the antioxidative enzymes. Plant Sci. 160: 415-423.

Rubio MC, Gonzalez EM, Minchin FR, Webb KJ, et al. (2002). Effect of water stress on antioxidant enzymes of leaves and nodules of transgenic alfalfa over expressing superoxide dismutases. Physiol. Plant 115:531-540.

Wang F, Dong L, Dai CJ, Lin Let.al. (2010). Molecular cloning and expression analysis of Cu/Zn superoxide dismutase gene (MrSOD1) cDNA from Myricarubra. Chin. Agric. Sci. Bull. 26: 27-33.

Wang F, Wang HB and Wang JF (2007). Sequence and expression analysis of cytoplasmic copper/zinc superoxide dismutase gene in rice. J. Trop. Subtrop. Bot. 15: 101-106.

Wang LY and Hong QH (2004). Real time quantitative PCR technique and its application. J. Cell Biol. 26: 62-67.

Zelko IN, Mariani TJ and Folz RJ (2002). Superoxide dismutase multigene family: a comparison of the CuZn-SOD (SOD1), Mn-SOD (SOD2), and EC-SOD (SOD3) gene structures, evolution, and expression. Free Radic. Biol. Med. 33: 337-349.

Zhu HL, Dong CH, Diao Y et al. (2006). Cloning and sequence analysis of the copper-zinc superoxide dismutase cdna from Nelumbo nucifera. Wuhan Univ. 52: 475-480. 